\title{
ЗАТРУДНЕНИЕ СЕТЕВОГО СКАНИРОВАНИЯ
}

\section{Кичанов Ростислав Вячеславович}

курсант

Краснодарское Высшее Военное Училище

Аннотация: В статье рассматривается вопрос предотвращения сетевого сканирования. Разновидности сетевых атак. Методы предотвращения сетевого сканирования посредством сетевых ловушек.

Ключевые слова: Сетевое сканирование, сетевые ловушки, демаскирующие признаки.

\section{DIFFICULTY NETWORK SCANNING}

\section{Kichanov Rostislav Vyacheslavovich}

\begin{abstract}
This article discusses the issue of preventing network scanning. Types of network attacks. Methods for preventing network scanning through network traps.
\end{abstract}

Key words: Network scanning, network traps, unmasking signs.

Сетевые атаки с каждым годом становятся разнообразнее и тем самым наносят колоссальный финансовый и репутационный ущерб. Атаки поражают все коммуникации и блокируют работу организации на продолжительный период времени. На сегодняшний телекоммуникационные и вычислительные сети стали регулярно подвергаться атакам как изнутри периметра, так и снаружи. В основном для обеспечения безопасности сетей применяется аппаратное и программное обеспечение, которое препятствует попыткам несанкционированного воздействия и исследования структуры. Применение злоумышленниками разнообразных стратегий воздействия в итоге может привести к обходу ими внешней защиты.

Разновидностей сетевых атак появляется все больше, так как злоумышленники постоянно совершенствуют методы нападения, результатом которых могут стать похищение конфиденциальной информации, выведение 


\section{МОЛОДЕЖНАЯ НАУКА КАК ФАКТОР И РЕСУРС \\ ОПЕРЕЖАЮЩЕГО РАЗВИТИЯ}

системы из строя либо ее полный "захват" с последующим использованием как части зомби-сети для совершения новых атак. Таким образом, сетевые атаки подразделяются на:

- Сетевое сканирование - это сведения из сети организации, которые собирают с помощью приложений, находящихся в свободном доступе. В частности, сканирование портов - злоумышленник сканирует UDP- и TCPпорты, которые используются сетевыми службами на атакуемом компьютере, и определяют уязвимость атакуемого компьютера перед более опасными видами вторжений;

- IP-спуфинг — хакер выдает себя за легитимного пользователя;

- Mail Bombing —это отказ работы почтового ящика или всего почтового сервера;

- DDoS-атаку - это отказ от обслуживания, когда обычные пользователи сайта или портала не могут им воспользоваться;

- Man-in-the-Middle - это внедрение в корпоративную сеть с целью получения пакетов, передаваемых внутри системы);

- XSS-атаку — это проникновение на ПК пользователей через уязвимости на сервере;

- Фишинг - это введение в заблуждение путем отправки сообщений с якобы знакомого адреса или подмена знакомого сайта на фальшивую копию.

- Применение специализированных приложений - вирусов, троянов, руткитов, снифферов;

- Переполнение буфера - это поиск программных или системных уязвимостей и дальнейшая провокация нарушение границ оперативной памяти, завершение работы приложения в аварийном режиме и выполнение любого двоичного кода.

- Атаки-вторжения - это сетевые атаки по «захвату» операционной системы атакуемого компьютера. Данный вид является самым опасным, поскольку в случае ее успешного завершения операционная система полностью переходит под контроль злоумышленника.

Одним из наиболее распространенных видов сетевых атак является сетевое сканирование. Сама по себе такая атака не несет какой-либо угрозы, но на основании информации, которую получили при сканировании, могут происходить другие атаки. 


\section{МОЛОДЕЖНАЯ НАУКА КАК ФАКТОР И РЕСУРС \\ ОПЕРЕЖАЮЩЕГО РАЗВИТИЯ}

Существуют различные методы предотвращения сетевого сканирования. Это методы пассивной и проактивной защиты. Данные методы направленны на формирование ложных представлений о структуре защищаемой сети и отвлечение внимания злоумышленника на второстепенные цели с использованием так называемых «сетевых ловушек» (network tarpits) и «сетевых приманок» (honeypots).

В пассивных средствах защиты используются вымышленные уязвимые сетевые узлы, которые представляются легкой целью для злоумышленника и привлекают его внимание. Анализ трафика, который получается такими узлами, дает возможность сформировать представление о предполагаемом нарушителе и общую схему его действий, используемую для корректной настройки иных средств защиты информации и предотвращения реальных атак впоследствии. В качестве дополнительного эффекта злоумышленник получает ложную информацию о структуре и топологии исследуемой им сети.

К изменениям результатов, получаемых при сканировании топологии сети, технология проактивной защиты позволяет не только нейтрализовать попытку несанкционированного доступа к защищаемой информации, но и провести ответную информационную атаку, позволяющую замедлить автоматическое сканирование вычислительной сети, значительно расходуя вычислительные ресурсы системы злоумышленника, а также ввести его в заблуждение о составе вычислительной сети, путем реализации следующих методов:

1. сканирование атакующего ресурса для сбора информации и определения дальнейших действий (версия ОС, используемый набор служб, приложений и т.д.);

2. непосредственная сетевая атака, например, типа «отказ в обслуживании» (DoS);

3. целевые атаки на основе полученных сведений о злоумышленнике.

Описанные выше методы позволяют не только понизить скорость средств автоматического сканирования сети, расходуя тем самым вычислительные и временные ресурсы злоумышленника, и ввести его в заблуждение о составе сети, но и провести ответную атаку, при этом предварительно получить достаточные сведения о цели. Дополнительное время, которое злоумышленник тратит на исследование сети, может быть использовано для определения его 
местоположения и принятия организационных мер по пресечению противоправных действий.

Таким образом, сетевые ловушки представляют возможность использования отдельных IP-адресов или их пулы (совокупности) в качестве ложных узлов сети. Имитируя конкретный «истинный» узел, ловушка отвечает на все входящие сетевые запросы вместо данного узла, при этом, в случае ТСРзапросов, используются механизмы контроля окна ТСР, сохраняя соединение открытым и не давая его завершить. При установлении ТСР-сессии объявляется о малом размере окна, которое впоследствии уменьшается до нуля.

Злоумышленник, в свою очередь, может использовать комплексы, которые могут обнаружить активность сетевых ловушек на основе их демаскирующих признаков, обусловленных особенностями алгоритмов функционирования ловушки. Условно они подразделяются на два класса:

Ненадежные демаскирующие признаки - это признаки, которые могут служить указанием на хост-ловушку, но не являются достаточно достоверным показателем наличия сетевой ловушки. К ним относятся следующие демаскирующие признаки.

«Параметры ТСР». Протокол ТСР дает возможность узлам согласовывать дополнительные функции в виде параметров ТСР (TCP options), таких как MSS, MTU, TTL и других. Как правило, они согласовываются операционной системой во время установления. Поскольку сетевые ловушки генерируют пакеты ТСР в обход сетевого стека операционной системы, любые опции ТСР должны быть согласованы непосредственно с сетевой ловушкой, что в данный момент на практике не реализовано - возвращается пустой список параметров, что является однозначным (именным) демаскирующим признаком «ловушки».

«Высокая плотность активных узлов сети». Подсеть, «обслуживаемая» сетевой ловушкой, при сканировании будет выглядеть так, как будто она полностью занята (в ней не будет неактивных узлов), ибо ловушка перехватывает и отвечает на все пакеты, целью которых является один из узлов данной подсети. На практике вероятность обнаружить полностью активную подсеть большого размера достаточно низка, чего нельзя сказать о сетях меньшего размера, поэтому по данному признаку также нельзя однозначно судить об использовании сетевой «ловушки».

«Множество открытых ТСР-портов». ІР-адрес, отвечающий на запросы ко всем ТСР-портам, очевидно, указывает на сетевую ловушку. Однако для 


\section{МОЛОДЕЖНАЯ НАУКА КАК ФАКТОР И РЕСУРС \\ ОПЕРЕЖАЮЩЕГО РАЗВИТИЯ}

определения набора открытых портов требуется 216 сканирований на узел. Кроме того, некоторые сетевые ловушки имеют возможность отвечать на обращение только к одному или же к небольшому числу портов. Именно поэтому злоумышленник может использовать этот признак только для устранения неоднозначности(снижения неопределенности).

Последующие демаскирующие признаки позволяют более точно судить о наличии сетевых ловушек в сети. «Размер окна ТСР». Основным критерием для обнаружения сетевых ловушек является управление потоком ТСР, поскольку зачастую используется точный, нестандартно низкий размер ТСР-окна, что и будет являться демаскирующим признаком сетевых ловушек.

«Ответ на уровне приложения». Характерный демаскирующий признак сетевых ловушек, который заключается в том, что даже если ловушки принимают ТСР-соединения, они не создают никакого ответа на уровне приложения.

«MAC-адрес». В некоторых сетевых ловушках не воплощен в жизнь механизм изменения МАС-адреса при ответе от имени различных сетевых узлов, что оказывается демаскирующим признаком. Его недостоверность обусловлена тем, что сетевые ловушки обычно используются для борьбы с угрозами за пределами локальной сети, это и не позволяет говорить о МАCадресе, как об отличительном признаке узла с сетевой ловушкой.

На основе алгоритма функционирования сетевой ловушки LaBrea авторами созданы способы снижения содержательности демаскирующих признаков средств проактивной защиты вычислительных сетей, которые в свою очередь позволяют сгладить их демаскирующие признаки, которые описаны выше.

Способ перемешивания размера ТСР-окна. Для понижения вероятности обнаружения ловушки было предложено случайно выбирать размер окна из промежутка от 0 до 255 байт. Данный способ не позволит сетевой «ловушке» создавать предпосылки демаскирующего признака при ответе на запрос.

Способ поддержки ТСР-опций. В исходной реализации LaBrea при формировании ТСР-пакетов не используются ТСР-опции. Для скрытия данного признака было решено копировать все ТСР-опции, кроме опции timestamp, из входящего пакета при формировании ответного. Таким образом, программыдетекторы сетевых ловушек, которые учитывают этот признак, уже не обнаружат разработанную ловушку. 
Способ формирования ответа на уровне приложения. Основной целью ловушек является наиболее продолжительное удержание активного соединениея со злоумышленником. Однако после установления ТСР-сессии и получения реальных данных ловушка их либо игнорирует, либо сбрасывают соединение, что влечет за собой ее компрометацию. Для исключения этого демаскирующего признака в алгоритме предусмотрена возможность ответа пакетом ТСР АCK на пакеты с данными уже после установления ТСР-сессии.

Способ перемешивания MAC-адресов. B ARP-ответах LaBrea указывает статический MAC-aдрес 00:00:0f:ff:ff:ff, что является именным демаскирующим признаком при нахождении злоумышленника в том же сегменте сети, что и ловушка. Для устранения данного признака предлагается использовать разработанный генератор МАС-адресов, при этом для каждого IP адреса должен генерироваться новый МAC-адрес.

Таким образом, сетевая ловушка, усовершенствованная посредством применения предложенных способов снижения содержательности демаскирующих признаков, обнаруживается детекторами сетевых ловушек с гораздо меньшим успехом, что говорит об эффективности разработанных способов снижения содержательности, демаскирующих признаков средств проактивной защиты вычислительных сетей.

\section{Список литературы}

1. Защита и безопасность ведом. интегрированных инфоком.-ционных систем/Р.В. Максимов, А.Е. Давыдов, О.К. Савицкий. Москва, 2015520 с.

2. Способ обнаружения удаленных атак на автоматиз. системы управления: пат. 2264649 Рос. Федерация, МПК G06F / заявитель и патентообладатель Военный универ-т связи (RU). Максимов Р. В., Андриенко А.А., Куликов О.Е., Костырев А.Л. № 2004112750; заявл. 26.04.2004; опубл. 20.11.2005, Бюл. № 32 .

3. Introduction to Cyberdeception / Neil C. Rowe, Julian Rrushi. USA $339 \mathrm{c}$.

4. T. Liston. LaBrea. 2003.

5. C. Ruvalcaba. Smart IDS - Hybrid LaBrea Tarpit. SANS Institute, Report, 2009.

(C) Р.В. Кичанов, 2022 